\title{
Umbilical Coiling Index and Its Relation to Perinatal Outcome
}

\author{
${ }^{[}$Asha DEVI ${ }^{a}{ }^{\circledR}$ Sreelatha RAMESH ${ }^{\mathrm{a}},{ }^{\circledR}$ Hamsalekha NAIK $^{\mathrm{a}},{ }^{\circledR}$ Srinivas HUCHEGOWDA ${ }^{\mathrm{b}}$ \\ aDepartment Obstetrics and Gynaecology, Employees' State Insurance Corporation Medical College and \\ Post Graduate Institute of Medical Science and Research, Bangalore, INDIA \\ ${ }^{b}$ Department of Biochemistry, Bowring Lady Curzon Medical College and Research Institute, Bangalore, INDIA
}

The article was presented orally in All India Conference of Obstetrics and gynaecology in Lucknow, India on $1^{\text {st }}$ February 2020.

\begin{abstract}
Objective: Umbilical cord is crucial to the development, well-being and survival of the fetus, but also being vulnerable to kinking, compressions, traction, and torsion which may affect the perinatal outcome. Abnormally coiled cords have been reported to be more frequent in cases with adverse perinatal outcome. It was aimed to evaluate the umbilical coiling index (UCI) postnatally and its association with perinatal morbidity and mortality. Material and Methods: We conducted a cross sectional study for over 12 months in ESIC MC \& PGIMSR, Bengaluru. A total of 321 term consenting parturient mothers with singleton live pregnancy in cephalic presentation were randomly selected by a single observer admitted in labour room irrespective of their parity. After delivery, the UCI was calculated as the number of complete coils divided by the total length of the cord in centimetres, UCI was grouped as hypocoiled $\left(<10^{\text {th }}\right.$ percentile $)$, normocoiled $\left(10^{\text {th }}\right.$ to $90^{\text {th }}$ percentile $)$ and hypercoiled $\left(>90^{\text {th }}\right.$ percentile). The statistical tests used were chi-square test and Fisher exact test in SPSS v24, p value of less than 0.05 was taken as statistically significant. Results: The mean UCI was $0.18+/-0.096$. Of the patients, $9.3 \%$ (30 out of 321 ) had hypocoiled (UCI $<0.082)$ and $9.7 \%(31$ patients) had hypercoiled (UCI $>0.316$ ). Hypercoiled is significantly associated with fetal distress $[\mathrm{OR}=13.5(0.003-0.008)] \mathrm{p}=0.001$, neonatal intensive care unit (NICU) admission [OR=19.14 (0.01 to 0.015)] $\mathrm{p}<0.001$ and meconium staining $[\mathrm{OR}=5.65(0.024-0.030)] \mathrm{p}=0.017$. It was also found that presence of nuchal cord in hypercoiled group was significantly associated with fetal distress $[\mathrm{OR}=4.661(0.052-0.061)] \mathrm{p}=0.031$. Conclusion: Abnormal UCI is associated with adverse perinatal outcome. Clinical significance: Antenatal detection of the coiling index can identify the fetuses at risk and thus help in timely intervention and further management.
\end{abstract}

Keywords: Umbilical cord; pregnancy outcome; fetal distress; meconium

The umbilical cord is the connecting stalk binding the developing fetus in-utero with the nourishing mother to-be. It provides a channel for the blood to reach fetal tissues, back and forth from the placenta, providing all the nourishment for fetal intrauterine life. Of the enlisted peculiarities of the umbilical cord, the most striking yet fascinating is the twisted fashion or spiraling course adopted by the component umbilical vessels. It is the spiraling of these blood vessels in the cord, which supposedly makes it sturdier to withstand buckling, compression and other forces. ${ }^{1-3}$

A coil is perceived to be of 360 degree complete turn or the spiral course of all the 3 vessels in a normal umbilical cord. Umbilical coiling index (UCI) is the ratio of the total number of coils divided by the total length of the umbilical cord in centimetres. Abnormal coiling indices may be a valuable predictor of adverse perinatal outcome and necessitate close fetal monitoring.

\section{NEED FOR THE STUDY}

Most of the fetuses with abnormally coiled cords, as established by the calculation of UCI, have a known normal outcome. Nevertheless, there appears to be a clinically relevant consistent association with abnormal coiling indices and a range of perinatal adversities. Many studies report that abnormal UCI is associated with fetal growth restriction (FGR), preterm delivery, abnormalities in fetal heart rate at 
term, acidotic $\mathrm{pH}$ in cord blood, meconium staining of liquor, chromosomal aberrations in fetus, increased rates of operative delivery for fetal distress, chorioamnionitis and also fetal death..$^{2-6}$ This association is supposedly due to abnormal flow or thrombus in the umbilical cord, which may lead to subsequent asphyxia and eventually fetal death. ${ }^{2}$ The difference in coiling has been postulated to be an antenatal marker of indicating fetuses at risk. It is unknown whether the UCI changes during antepartum or any adaptation of the coiling index alters the blood flow to the fetus. But it is still remains unverified whether, abnormal coiling could be one of the causes of underlying pathology, or merely a sequelae or both. It is believed that abnormal cord coiling, established during later gestation may have acute (foetal intolerance to labour and foetal demise) and in early gestation, chronic (growth retardation) effects on foetal wellbeing. Hence the significance of a detailed evaluation of the umbilical cord and the coiling index, when integrated into the antenatal fetal assessment, compliments information for better interpretation in high-risk pregnancies. ${ }^{7}$ Our study aims to evaluate the UCI postnatally and identify its association with pregnancy outcome considering various adverse perinatal events.

\section{MATERIAL AND METHODS}

The ethics committee approval was obtained from the Institutional Ethics Committee (ESIC MC\&PGIMSR) bearing the letter no.532/L/ 11/12/Ethics/ESICMC\& PGIMSR/Estt.Vol..III dated 2/1/2017. After obtaining the ethical clearance from the institute's scientific research council, the study was carried out in accordance with the Helsinki Declaration Principles. A cross sectional analytical study of umbilical cords of parturient mothers was conducted in the Department of Obstetrics and Gynaecology, Employees' State Insurance Corporation (ESIC) Medical College and Post Graduate Institute of Medical Science and Research (PGIMSR), Bangalore. Parturients getting admitted to the labour ward were randomly selected by a single observer over a period of 12 months. Only deliveries after 37 weeks of gestation with singleton, live babies with cephalic presentations irrespective of parity were included in the study after obtaining informed consent. Multiple pregnancies, malpresentations, preterm deliveries and previously diagnosed intrauterine death (IUD) as well as anomalous babies were excluded. Other abnormal cord characteristics excluded were cord prolapse, vasa previa, velamentous cord insertion, single umbilical artery, true knots, cords with indeterminate or incomplete turns, torsion, thrombosis and neoplasms, which are known to have detrimental effects on fetal prognosis. ${ }^{8}$

Upon recruitment, each patient's data sheet was completed. Maternal demographic characteristics like age, parity, medical and obstetrical events and neonatal problems were noted. The data sheet also contained in-detail information regarding other sociodemographic variables, complications occurred during antenatal and intrapartum period, chorioamnionitis and liquor abnormalities like meconium staining, gestation at delivery, mode of birth, abnormalities of fetal heart rate and neonatal outcome. Upon delivery, the cord was clamped at the newborn's end and cut with scissors at $5 \mathrm{~cm}$ from the site of cord insertion at umbilicus. Milking of the cord was avoided as it may affect the UCI. Active management of $3^{\text {rd }}$ stage of labour was conducted allowing the placenta to separate spontaneously. Any significant postpartum events like postpartum hemorrhage, genital tract injuries, uterine inversion, or postpartum collapse when present were noted. The length of the cord from the interrupted portion at the fetal end to the site of placental insertion was scaled in centimetres. Undue traction was not exerted on the cord to avoid errors at the time of measurement. Five centimetres was then added to calculate the total length of the cord. The number of coils in the total length of the cord was counted and UCI was measured. Other cord parameters like direction of coils, nuchal cords or false knots when present were noted. Neonatal factors like weight at birth, Apgar score, admission to neonatal intensive care unit (NICU), and presence of any congenital anomaly necessitating exclusion from the study were also noted.

The sample size (n) for our study was determined based on an assumed average of $24 \%$ prevalence rate of abnormal UCI from published series..$^{9-11}$ It was calculated using the formula: $\mathrm{n}=\mathrm{z}^{2 *} \mathrm{p} *(1-$ p) $/ \mathrm{e}^{2}$ where $\mathrm{z}=1.96$ for a confidence level $(\alpha)$ of $95 \%$, 
$\mathrm{p}=$ proportion (expressed as a decimal), $\mathrm{e}=$ margin of error $(0.05)$ and $n=(1.96)^{2 *} 0.24 *(1-0.24) /(0.05){ }^{2}$ Sample size calculated was 280 , however 321 participants meeting the inclusion criteria in the study period were recruited after consent. After the intended number of samples were collected, the mean UCI was calculated. Based on the mean UCI, they were grouped as hypocoiled, normocoiled and hypercoiled, as follows (defined by Rana et al. in 1995). ${ }^{4}$

Hypocoiled- $<10^{\text {th }}$ percentile

- Normocoiled- $10^{\text {th }}$ to $90^{\text {th }}$ percentile

- Hypercoiled- $>90^{\text {th }}$ percentile

The abnormally coiled groups, i.e. hypocoiled and hypercoiled were compared with the normocoiled group, and the associations of the UCI with the chosen maternal and foetal parameters were studied.

\section{STATISTICAL ANALYSIS}

Chi-square test was applied to $2 \times 2$ contingency table and data are presented as frequency distribution along with odds ratio and $95 \%$ confident interval. For samples less than 5, Fisher's exact test was used and $\mathrm{p}$ value $<0.05$ was taken as statistically significant. Data were analysed using SPSS statistical software version 24.

\section{RESULTS}

During the course of our study, we evaluated a total of 321 umbilical cords at birth from parturient mothers. The mean length of umbilical cord was found to be $54.9 \pm 10.2 \mathrm{~cm}$. The mean number of coils was $10.09 \pm 6.2$. The frequency distribution of UCI in our study group is presented in Table 1, Figure 1.

Using the established parameters as described earlier, the sample UCI were classified into hypocoiled, normocoiled, and hypercoiled groups, hypocoiled group with indices less than 0.083 coils/cm and hypercoiled group with values more than 0.316 coils $/ \mathrm{cm}$ and the rest in normocoiled group. The mean UCI was $0.18 \pm 0.096$. Normocoiled cord was predominant in our study comprising of $81 \%$ of the cases ( 260 of 321 ), where as abnormally
TABLE 1: Frequency distribution of the umbilical coiling index $(n=321)$.

\begin{tabular}{|lcc|}
\hline & $\begin{array}{c}\text { Mean } \pm \text { Standard } \\
\text { deviation }\end{array}$ & $\begin{array}{c}\text { Median (10 } \\
\mathbf{9 0 ^ { \text { th } }} \text { percentile) }\end{array}$ \\
\hline Cord length & $54.9 \pm 10.2$ & $54(44-66.8)$ \\
Total no. of coils & $10.09 \pm 6.2$ & $8(4-18)$ \\
Umblical coiling index & $0.18 \pm 0.096$ & $0.162(0.083-0.316)$ \\
Coiling index groups & Coiling index range & Distribution $(\mathrm{n})$ \\
$\cdot$ Hypocoiled & $0.00-0.082$ & 30 \\
• Normocoiled & $0.083-0.316$ & 260 \\
• Hypercoiled & $\geq 0.317$ & 31 \\
\hline
\end{tabular}

The study population is grouped into hypocoiled, normocoiled and hypercoiled groups based on the coiling index, the frequency distribution is mentioned accordingly.

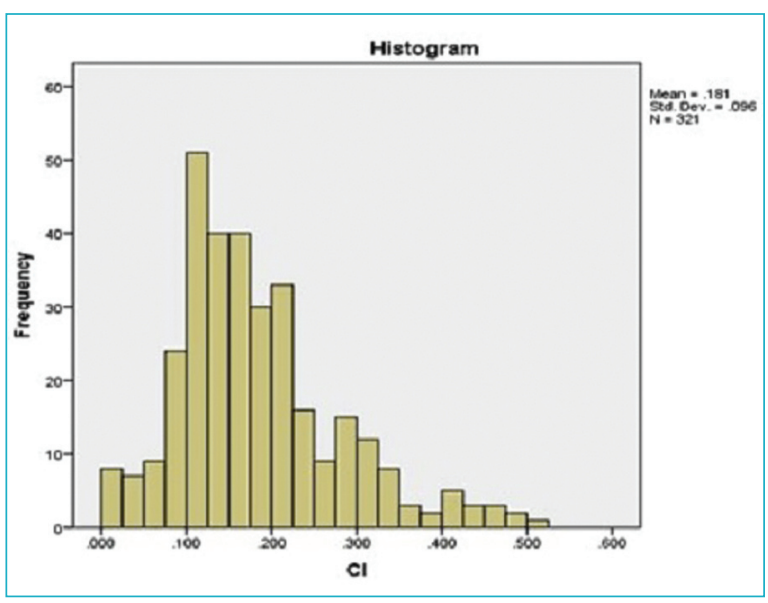

FIGURE 1: Schematic representation of umbilical coiling index distribution ( $n=321)$.

coiled cords made up for the rest 19\% (hypocoiled in 30 cases and hypercoiled in 31 cases). Dextral (clockwise) coils were noted in $16.8 \%$ whereas majority of the cords i.e. $82.2 \%$ demonstrated sinistral (anticlockwise) turns.

In our study group, 139 participants were primigravida (43.3\%) and 182 participants were multigravida (56.7\%). Approximately $81 \%$ of women $(260$ of 321) were aged below 30 years and 61 (19\%) women were above 30 years. As seen from the Table 2 , UCI doesn't vary significantly with advancing gestational age at term.

On comparing the neonates with hypocoiled cords and normocoiled cords, there was a statistically significant higher incidence of low Apgar score at birth $(p=0.007)$, neonates with hypocoiled cords have 


\begin{tabular}{|c|c|c|c|c|c|c|}
\hline $\mathrm{N}=321$ & $\begin{array}{l}\text { Frequency } \\
\text { distribution }\end{array}$ & $\begin{array}{l}\text { Normocoiled } \\
\qquad \mathrm{N}=260\end{array}$ & $\begin{array}{l}\text { Hypocoiled } \\
\qquad \mathrm{N}=30\end{array}$ & $\begin{array}{c}\text { p value } \\
\text { (hypocoiled vs normocoiled) }\end{array}$ & $\begin{array}{c}\text { Hypercoiled } \\
\quad \mathrm{N}=31\end{array}$ & $\begin{array}{l}\text { p value } \\
\text { (hypercoiled vs normocoiled) }\end{array}$ \\
\hline \multicolumn{7}{|c|}{ Maternal age (yrs) } \\
\hline Age $<30$ & $260(81 \%)$ & 215 & 23 & \multirow[t]{2}{*}{$p=0.57$} & 22 & \multirow[t]{2}{*}{$p=0.179$} \\
\hline Age $>30$ & $61(19 \%)$ & 45 & 7 & & 9 & \\
\hline \multicolumn{7}{|c|}{ Parity } \\
\hline Primi & $139(43.31 \%)$ & 108 & 16 & \multirow[t]{2}{*}{$p=0.29$} & 15 & \multirow[t]{2}{*}{$p=0.59$} \\
\hline Multi & $182(56.69 \%)$ & 152 & 14 & & 16 & \\
\hline \multicolumn{7}{|c|}{ Gestational age(wks) } \\
\hline $37-37.6$ & $84(26.2 \%)$ & 69 & 6 & \multirow[t]{4}{*}{$p=0.639$} & 9 & \multirow[t]{4}{*}{$p=0.417$} \\
\hline $38-38.6$ & $126(39.3 \%)$ & 103 & 11 & & 12 & \\
\hline $39-39.6$ & 87 (27.1\%) & 68 & 9 & & 10 & \\
\hline 40 and above & $24(7.5 \%)$ & 20 & 4 & & 0 & \\
\hline
\end{tabular}

The distribution of maternal demographic factors and its relationship with umbilical coiling index is described and presented as percentage distribution. Chi-square test is applied between different groups (normocoiled v/s hypocoiled and normocoiled v/s hypercoiled) and $p<0.05$ is taken as statistically significant.

3.7 times higher risk of having Agpar score $<7$ at 5 min when compared with normocoiled group. Similarly, neonates with hypercoiled cords when compared with those with normocoiled cords, significantly higher perinatal morbidity in terms of meconium stained liquor and fetal distress with lower Apgar scores at birth as well as need for NICU admission (Table 3). In our study, 42 newborns out of 321 required admission to NICU, among them 30 had normocoiled cords and 12 had hypercoiled cords. The comparison between the hypercoiled and normocoiled groups for NICU admission showed $p$ value $<0.001$. Neonates with hypercoiled cords at birth have 3 times higher risk of meconium at birth $(p=0.039)$, almost 4 times increased risk of fetal dis- tress $(\mathrm{p}=0.001)$, and more than 4 times increased possibility of requiring admission to NICU $(p=<0.001)$ and almost 5 times higher chances of low Apgar score of $<7$ at $5 \min (p=<0.001)$ on comparison with normocoiled group.

\section{DISCUSSION}

Umbilical cord is crucial for the gradual development, well being and overall survival of the fetus, nevertheless it is also evidently vulnerable to kinks/compressions, torsion and traction which in turn affect the fetal outcome. The integrity of the vessels in the cord is sustained by two important factors, Wharton's jelly and spiral/helical coiling. The blood

\begin{tabular}{|c|c|c|c|c|c|}
\hline Perinatal outcome (n) & $\begin{array}{l}\text { Normocoiled } \\
\qquad \mathrm{N}=260\end{array}$ & $\begin{array}{l}\text { Hypocoiled } \\
\mathrm{N}=30\end{array}$ & $\begin{array}{l}\text { Odd ratio }(95 \% \mathrm{Cl}), \mathrm{p} \text { value } \\
\text { (hypocoiled vs normocoiled) }\end{array}$ & $\begin{array}{l}\text { Hypercoiled } \\
\qquad \mathrm{N}=31\end{array}$ & $\begin{array}{l}\text { Odd ratio ( } 95 \% \mathrm{Cl}), \mathrm{p} \text { value } \\
\text { (hypercoiled vs normocoiled) }\end{array}$ \\
\hline Foetal distress present (67) & 50 & 2 & $0.3(0.076-1.3), p=0.129$ & 15 & $3.93(1.8-8.49), p=0.001^{*}$ \\
\hline Meconium in liquor (30) & 23 & 0 & NA & 7 & $3.0(1.1-7.7), p=0.039^{*}$ \\
\hline NICU admission (42) & 30 & 0 & NA & 12 & $4.84(2.13-10.96), p=<0.001^{*}$ \\
\hline Nuchal cord present (49) & 35 & 6 & $1.61(0.61-4.2), p=0.48$ & 8 & $2.2(0.92-5.3), p=0.11$ \\
\hline Apgar at $5 \mathrm{~min},<7(41)$ & 23 & 8 & $3.7(1.5-9.3), p=0.007^{*}$ & 10 & $4.9(2.0-11.6), p=<0.001^{*}$ \\
\hline Birth weight $<2.5 \mathrm{~kg}$ & 37 & 2 & $0.4(0.98-1.8), p=0.39$ & 5 & $0.16(0.42-3.2), p=0.787$ \\
\hline Birth weight $>2.5 \mathrm{~kg}$ & 223 & 28 & & 26 & \\
\hline
\end{tabular}

NICU: Neonatal Intensive Care Unit, NA: Not Applied.

The distribution of perinatal risk factors and its relationship with umbilical coiling index is presented as frequency distribution. Chi-square test is applied between different groups (normocoiled v/s hypocoiled and normocoiled v/s hypercoiled) and data represented as odd ratio with $95 \%$ confident interval, $p<0.05$ is taken as statistically significant. 
vessels along the length of the cord, ( 2 umbilical arteries, 1 umbilical vein) traverse in a helical fashion/spiral course. ${ }^{4,9}$ This is a unique characteristic of the cord, first recorded in literature as early as 1521.A.D by Berengarius, as mentioned by Edmonds. ${ }^{10}$ The coiling of the umbilical cord appears to provide turgor and reinforcement, resulting in a conduit, both strong and flexible. ${ }^{3}$

The genesis of coiling of umbilical cord is not specifically known. Many hypotheses proposed are, movements of fetus within the womb, passive or active torsion of the fetus/embryo, fetal hemodynamic factors, difference in growth rates of cord vessels and the disposition of the muscle fibres in the umbilical arterial wall. ${ }^{10,11}$ The coiling of the cord is said to originate earliest on the $28^{\text {th }}$ day and apparently in $95 \%$ of the early developing foetuses by the $9^{\text {th }}$ week of conception. ${ }^{12}$ During the $1^{\text {st }}$ trimester of pregnancy the helices of the coils can be seen on ultrasonographic examination. ${ }^{12}$ The visualised number of coils in $1^{\text {st }}$ trimester is more or less, equivalent to that of the term cords and the total number of twists observed are 0 and $40 .{ }^{13}$ Cords show a tendency of more spirality towards the fetal end than the placental bed. Also lengthening of the cord is said to occur from the fetal end, thus umbilical coiling may represent an evidence of long-term effects on overall fetal health status. ${ }^{5,13}$

The mean UCI in our study was $0.18 \pm 0.096$, which is in consensus with other studies [Rana et al.

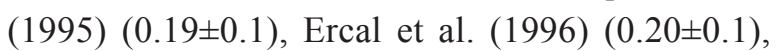
Strong et al. (1994) $(0.21 \pm 0.07)] \cdot 3,4,14$ The $10^{\text {th }}$ and $90^{\text {th }}$ percentile values of frequency distribution for UCI observed in our study were also in agreement with these studies and a meta-analysis on UCI showed the normal coiling index to be around $0.17 \pm 0.009$ completed spirals per centimetre. ${ }^{3,4,8,14}$

The direction of umbilical coils in our study was found to be predominantly anticlockwise (sinistral). The anticlockwise coiling of umbilical cord was reported in the works of Chaurasia et al. 1979, Lacro et al. (1987), Hickey et al. (1993), the reason behind this feature remains unexplained. ${ }^{12,15,16}$ However the consensus is that forceful paddling with fetal right arm in an already established handedness can be taken into consideration. ${ }^{17}$ This theory is contradicted by Lacro et al. (1987), stating that there is no correlation between direction of coiling and handedness of either mother or fetus. ${ }^{12}$

UCI was not affected by gestational age at delivery, maternal age, parity and birth weight of the neonate in our study which is consistent with van Dijk et al. (2002) who studied UCI in 371 deliveries. ${ }^{18}$ However, Ezimokhai et al. have reported that hypercoiling is a more common occurrence in extremes of age groups studied by them (below 20 and above 35 years). ${ }^{6}$ No other studies found any significance with age and umbilical coiling.

Our study did not find UCI to have any significant association with parity, anaemia and Gestational Diabetes Mellitus (Table 4). However, we found a positive correlation between polyhydramnios and hypertension in pregnancy with hypercoiling. This is also supported by Edmond's hypothesis relating the coiling of the cord to the rotational movement imparted by the early embryo, and when there is excess liquor amnii, increased movements result in further coiling. ${ }^{10}$ On the contrary, Kashanian et al. found oligohydramnios to be associated with both forms of abnormal coiling. ${ }^{19}$ In our study, oligohydramnios had a no association with either hypocoiled or hypercoiled cords.

Strong et al. (1993) and Machin et al. (2000) reported an association of FGR with hypocoiling and quoting that hypocoiled cords are more vulnerable to compression and over time, result in decreased fetoplacental circulation, and consequently to growth restricted babies. ${ }^{2,5}$ On the contrary, Ezimokhai et al. and de Laat et al. found FGR to be associated with hypercoiling. ${ }^{6,8,20}$ Our study demonstrated no significant association between growth restricted neonates and hypo-or hypercoiled cords. However, other adverse effects of abnormally coiled cords have been documented abundantly in the obstetric literature. , $8,20-22^{2}$

Interestingly, hypocoiled group in our study was associated with significantly lower operative deliveries including caesarean section $(\mathrm{p}=0.031)$ compared to normocoiled group. Strong et al. (1993) also reported significantly higher incidence of intrapartum Fetal Heart Rate (FHR) variations, operative deliv- 


\begin{tabular}{|c|c|c|c|c|c|}
\hline Outcome & $\begin{array}{c}\text { Normocoiled } \\
\mathrm{N}=260\end{array}$ & $\begin{array}{l}\text { Hypocoiled } \\
\qquad \mathrm{N}=30\end{array}$ & $\begin{array}{l}\text { Odds ratio (95\% Cl), p value } \\
\text { (hypocoiled vs normocoiled) }\end{array}$ & $\begin{array}{l}\text { Hypercoiled } \\
\qquad \mathrm{N}=31\end{array}$ & $\begin{array}{l}\text { Odds ratio }(95 \% \mathrm{Cl}), \mathrm{p} \text { value } \\
\text { (hypercoiled vs normocoiled) }\end{array}$ \\
\hline Oligohydramnios & 31 & 5 & $1.48(0.53-4.14), p=0.39$ & 2 & $0.5(0.1-2.2), p=0.55$ \\
\hline Hypertensive disorders & 26 & 2 & $0.64(0.14-2.85), p=0.751$ & 6 & $2.1(0.81-5.7), p=0.128$ \\
\hline Anaemia & 21 & 1 & $0.39(0.05-3.03), p=0.71$ & 1 & $0.38(0.05-2.92), p=0.48$ \\
\hline PROM & 8 & 1 & $1.09(0.13-9), p=1.0$ & 1 & $1.05(0.13-8.69), p=1.0$ \\
\hline GDM & 15 & 1 & $0.56(0.07-4.42), p=1.0$ & 1 & $0.5(0.06-3.9), p=1.0$ \\
\hline Polyhyrodramnios & 4 & 0 & NA & 1 & $2.1(0.23-19.7), p=0.433$ \\
\hline IUGR & 28 & 1 & $0.28(0.03-2.17), p=0.33$ & 3 & $0.88(0.25-3.10), p=1.0$ \\
\hline $\begin{array}{l}\text { Mode of delivery } \\
\text { operative deliveries inc. } \\
\text { LSCS } 155(48.3 \%)\end{array}$ & 132 & 9 & $0.41(0.18-0.94), p=0.031^{*}$ & 14 & $0.8(0.38-1.69), p=0.57$ \\
\hline $\begin{array}{l}\text { Spontaneous vaginal delivery } \\
166(51.7 \%)\end{array}$ & 128 & 21 & & 17 & \\
\hline
\end{tabular}

PROM: Premature Rupture Of Membranes, GDM: Gestational Diabetes Mellitus, IUGR: Intra Uterine Growth Restriction, LSCS: Lower Segment Caeserean Section, NA: Not Applied. The distribution of maternal risk factors, medical disorders and its relationship with umbilical coiling index is presented as frequency distribution. Chi-square test is applied between different groups (normocoiled v/s hypocoiled and normocoiled v/s hypercoiled) and data represented as odd ratio with $95 \%$ confident interval, $p<0.05$ is taken as statistically significant. 21 out of 30 cases with hypocoiled cords underwent spontaneous vaginal delivery showing statistical significance $(p=0.031)$.

ery for fetal distress and meconium staining in normocoiled cords when compared with hypocoiled cord. ${ }^{5}$ In our study we did not find any statistical significance between the two groups with respect to FHR disturbances and meconium staining except for operative deliveries for fetal distress, this could be because, in our study, data on caesarean sections included all obstetric indications, not only those with fetal compromise.

Intrapartum FHR variations depicting acute fetal distress was significantly associated with hypercoiled group in our study, $(\mathrm{p}=0.001)$. de Laat et al. found a strong association with hypercoiling and birth asphyxia-both acute and chronic. ${ }^{8,20}$ In case of hypercoiled cords, flow dynamic principles and other studies explain the fact that, flow through a coiled tube is associated with more resistance to flow when compared to a straight tube. ${ }^{23}$ Studies in literature also quote a consistent association between intrapartum decelarations in FHR and UCI abnormal indices. . $^{5,8,19}$ Out of 30 hypocoiled cases, 5 had absent coils but with presence of nuchal cords. While hypocoiled cords are strongly associated with nuchal cords, thus resisting one of the major problems caused by nuchal cords, i.e. occlusion of the cord when stretching around the fetal neck there by reducing the occurrence of FHR variations during labour. ${ }^{24}$ However, the concern with tight nuchal cords is not cord compression, rather compression on the fetal carotid arteries. Further studies with larger sample size may provide greater insight in proving these hypotheses.

The major observations in our study were the association of hypercoiled cords in new borns with meconium stained liquor ( $p=0.039$ ), lower Apgar score at $5 \mathrm{~min}(\mathrm{p}<0.001)$ and neonatal hospitalisations $(p<0.001)$. Strong et al. studied 100 umbilical cords and found that meconium staining was associated with hypercoiled cords with the $p$ value of 0.03 which was highly significant but did not reason it. ${ }^{3,5}$ In another study by Deepika Chholak et al. involving 500 cases, they found that the meconium staining was significantly associated with hypercoiled group..$^{25}$ Several other studies have also correlated hypercoiled cords with poor perinatal outcome such as meconium staining of liquor and Intra Uterine Growth Restriction (IUGR). ${ }^{3-6,25-27}$ A study by Hasegawa et al. has reported that hyper-coiled cords are less flexible or more prone to kinking, torsion in labour, thus leading to hypoxia. ${ }^{28}$ de Laat et al. and Razak et al. noted that increasing UCI may benefit by increasing umbilical blood flow, resulting in localized pulsometer effects, but coiling when increased further may lead to compression-mediated flow reduction and predispose to vascular throm- 
boses. ${ }^{29,30}$ Indeed, over-coiling alone, even in the absence of cord stricture, has been documented at autopsy in $23 \%$ of intrauterine fetal deaths. ${ }^{31}$

An initial low Apgar ( $<7$ at 5 minutes) was significantly associated with both hypocoiled and hypercoiled UCI (compared to those with normocoiled groups) in our study, a result similar was reported by Gupta et al. and Kashanian et al. de Laat et al. (2006) in their study of 885 cases, found that low Apgar scores was associated with hypocoiled group, as in other studies. ${ }^{9}, 19,20,32-34$

Birth weight was not found to be significantly associated with any of the abnormally coiled groups in our study but this is not in agreement with other studies. ${ }^{4,21,35}$ However, no satisfactory explanation for this association has been determined.

\section{LIMITATION OF STUDY}

All obstetric indications for cesarean sections were included in our study except malpresentations, thus limiting us from drawing valuable conclusion with respect to cesarean sections exclusively with fetal distress. Also, thinning of Wharton's jelly is associated with adverse perinatal outcome, measuring the amount of Wharton jelly and addressing the confounding effect was another possible limitation in our study.

\section{SCOPE FOR FURTHER STUDY}

With the perspective of preventive obstetrics, any further study for FHR variations may reveal if there are, indeed, specific rhythm disturbances in FHR correlating with abnormal UCI. If found, clarity would be obtained for deciding upon the speed and mode of delivery. Similarly, it is not asserted if any other neonatal neurological morbidity [e.g., specific types of Hypoxic Ischaemic Encephalopathy (HIE) or cerebral palsy] may correlate with cord abnormalities or abnormal cord coiling, which has been found to be associated periventricular leukomalacia. ${ }^{2}$

Umbilical coiling by ultrasonography is said to have a potential value in second trimester screening and term pregnacy, with a sensitivity of $78.9 \%$ and $25.4 \%$ to predict the hypocoiling and hypercoiling respectively (Predanic et al.) especially when multiple loops of nuchal cords or entangled cords with fetal limbs are identified, thus avoiding further catastrophes. ${ }^{36-38}$

\section{CONCLUSION}

Our present study indicates that abnormal coiling indices are associated with adverse perinatal outcomes. In the near future, ultrasonographic evaluation of the umbilical cord and the UCI may become an integral part of antenatal fetal assessment and surveillance in high risk pregnancies, paying close attention to patients exhibiting abnormal coiling, combined with thinning of Wharton's jelly and nuchal cord entanglement.

\section{Acknowledgement}

I sincerely thank all the subjects who participated in the study and the faculty and support staff of the Department of Obstetrics \& Gynecology, ESIC Medical College and PGIMSR, Bengaluru, Karnataka for their co-operation.

\section{Source of Finance}

During this study, no financial or spiritual support was received neither from any pharmaceutical company that has a direct connection with the research subject, nor from a company that provides or produces medical instruments and materials which may negatively affect the evaluation process of this study.

\section{Conflict of Interest}

No conflicts of interest between the authors and / or family members of the scientific and medical committee members or members of the potential conflicts of interest, counseling, expertise, working conditions, share holding and similar situations in any firm.

\section{Authorship Contributions}

Idea/Concept: Asha Devi, Sreelatha Ramesh, Srinivas Huchegowda; Design: Asha Devi, Sreelatha Ramesh, Srinivas Huchegowda; Control/Supervision: Asha Devi, Sreelatha Ramesh, Hamsalekha Naik; Data Collection and/or Processing: Asha Devi, Sreelatha Ramesh, Hamsalekha Naik, Srinivas Huchegowda; Analysis and/or Interpretation: Asha Devi, Sreelatha Ramesh, Srinivas Huchegowda; Literature Review: Asha Devi, Sreelatha Ramesh; Writing the Article: Asha Devi, Srinivas Huchegowda; Critical Review: Sreelatha Ramesh, Hamsalekha Naik; References and Fundings: Asha Devi, Sreelatha Ramesh; Materials: Asha Devi, Sreelatha Ramesh, Hamsalekha Naik. 


\section{REFERENCES}

1. Evans MJ. Review: diabetes and pregnancy: a review of pathology. Br J Diabetes Vasc Dis. 2009;9(5):201-6. [Crossref]

2. Machin GA, Ackerman J, Gilbert-Barness E. Abnormal umbilical cord coiling is associated with adverse perinatal outcomes. Pediatr Dev Pathol. 2000;3(5):462-71. [Crossref] [PubMed]

3. Strong TH Jr, Jarles DL, Vega JS, Feldman DB. The umbilical coiling index. Am J Obstet Gynecol. 1994;170(1 Pt 1):29-32. [Crossref] [PubMed]

4. Rana J, Ebert GA, Kappy KA. Adverse perinatal outcome in patients with an abnormal umbilical coiling index. Obstet Gynecol. 1995;85(4):573-7. [Crossref] [PubMed]

5. Strong TH Jr, Elliott JP, Radin TG. Non-coiled umbilical blood vessels: a new marker for the fetus at risk. Obstet Gynecol. 1993;81(3):40911. [PubMed]

6. Ezimokhai M, Rizk DE, Thomas L. Maternal risk factors for abnormal vascular coiling of the umbilical cord. Am J Perinatol. 2000;17(8): 441-5. [Crossref] [PubMed]

7. Sebire NJ. Pathophysiological significance of abnormal umbilical cord coiling index. Ultrasound Obstet Gynecol. 2007;30(6):804-6. [Crossref] [PubMed]

8. de Laat MW, Franx A, van Alderen ED, Nikkels PG, Visser GH. The umbilical coiling index, a review of the literature. J Matern Fetal Neonatal Med. 2005;17(2):93-100. [Crossref] [PubMed]

9. Gupta S, Faridi MMA, Krishnan J. Umbilical coiling index. J Obstet Gynecol India. 2006;56(4):315-9. [Link]

10. Edmonds HW. The spiral twist of the normal umbilical cord in twins and in singletons. Am J Obstet Gynecol. 1954;67(1):10220. [Crossref] [PubMed]

11. Chitra T, Sushanth YS, Raghavan S. Umbilical coiling index as a marker of perinatal outcome: an analytical study. Obstet Gynecol Int. 2012;2012:213689. [Crossref] [PubMed] [PMC]

12. Lacro RV, Jones KL, Benirschke K. The umbilical cord twist: origin, direction, and relevance. Am J Obstet Gynecol. 1987;157(4 Pt 1):833-8. [Crossref] [PubMed]

13. Sepulveda W. Time for a more detailed prenatal examination of the umbilical cord? UItrasound Obstet Gynecol. 1999;13(3):157-60. [Crossref] [PubMed]

14. Ercal T, Lacin S, Altunyurt S, Saygili U, Cinar $O$, Mumcu A. Umbilical coiling index: is it a marker for the foetus at risk? Br J Clin Pract. 1996;50(5):254-6. [PubMed] 971-2. [Crossref] [PubMed]
15. Chaurasia BD, Agarwal BM. Helical structure of the human umbilical cord. Acta Anat (Basel). 1979;103(2):226-30. [Crossref] [PubMed]

16. Hickey K, McKenna P. Chirality in the umbilical cord. Br J Obstet Gynaecol. 1993;100(10):

17. Ezimokhai M, Rizk DE, Thomas L. Abnormal vascular coiling of the umbilical cord in gestational diabetes mellitus. Arch Physiol Biochem. 2001;109(3):209-14. [Crossref] [PubMed]

18. van Diik CC, Franx A, de Laat MW, Bruinse HW, Visser GH, Nikkels PG. The umbilical coiling index in normal pregnancy. J Matern Fetal Neonatal Med. 2002;11(4):280-3. [Crossref] [PubMed]

19. Kashanian M, Akbarian A, Kouhpayehzadeh $\mathrm{J}$. The umbilical coiling index and adverse perinatal outcome. Int J Gynaecol Obstet. 2006;95(1):8-13. [Crossref] [PubMed]

20. de Laat MW, Franx A, Bots ML, Visser GH, Nikkels PG. Umbilical coiling index in normal and complicated pregnancies. Obstet Gynecol. 2006;107(5):1049-55. [Crossref] [PubMed]

21. Ernst LM, Minturn L, Huang MH, Curry E, Su EJ. Gross patterns of umbilical cord coiling: correlations with placental histology and stillbirth. Placenta. 2013;34(7):583-8. [Crossref] [PubMed]

22. Khong TY. Evidence-based pathology: umbilical cord coiling. Pathology. 2010;42(7):61822. [Crossref] [PubMed]

23. Garber A, Hernandez L, Mullin C, Simon M. Pressure flow through a coiled tube. Group M5, BE 310 Spring 2004. [Link]

24. Strong TH Jr, Manriquez-Gilpin MP, Gilpin BG. Umbilical vascular coiling and nuchal entanglement. J Matern Fetal Med. 1996;5(6):35961. [Crossref] [PubMed]

25. Chholak D, Gupta P, Khajotia S. Study to evaluate association of umbilical coiling index and perinatal outcome. Int J Reprod Contracept Obstet Gynecol. 2017;6(2):408-12. [Crossref]

26. Ek S, Andersson A, Johansson A, Kublicas M. Oligohydramnios in uncomplicated pregnancies beyond 40 completed weeks. A prospective, randomised, pilot study on maternal and neonatal outcomes. Fetal Diagn Ther. 2005;20(3):182-5. [Crossref] [PubMed]

27. Nakamura M, Hasegawa J, Matsuaka R, Mimura T, Ichizuka K, Sekizawa A, et al. Risk analysis for the birth of a small for gestational age (SGA) infant. The Internet Journal of Gynecology and Obstetrics. 2009;13(2):1-5. [Crossref]

28. Hasegawa J, Mimura T, Morimoto T, Matsuoka R, Ichizuka K, Sekizawa A, et al. Detection of umbilical venous constriction by Doppler flow measurement at midgestation. Ultrasound $\mathrm{Ob}$ stet Gynecol. 2010;36(2):196-201. [Crossref] [PubMed]

29. de Laat MW, van Alderen ED, Franx A, Visser GH, Bots ML, Nikkels PG. The umbilical coiling index in complicated pregnancy. Eur $\mathrm{J} \mathrm{Ob-}$ stet Gynecol Reprod Biol. 2007;130(1):66-72. [Crossref] [PubMed]

30. Razak K, Meena D, GI M. "Coils and Kinks": a novel technique to evaluate the perinatal outcome. Gynecol Obstet. 2017;7(11):1-9. [Crossref]

31. Peng $H Q$, Levitin-Smith $M$, Rochelson $B$, Kahn E. Umbilical cord stricture and overcoiling are common causes of fetal demise. Pediatr Dev Pathol. 2006;9(1):14-9. [Crossref] [PubMed]

32. Jo YS, Jang DK, Lee $G$. The sonographic umbilical cord coiling in late second trimester of gestation and perinatal outcomes. Int J Med Sci. 2011;8(7):594-8. [Crossref] [PubMed] [PMC]

33. Sharma B, Bhardwaj N, Gupta S, Gupta PK, Verma A, Malviya K. Association of umbilical coiling index by colour Doppler ultrasonography at 18-22 weeks of gestation and perinatal outcome. J Obstet Gynaecol India. 2012;62(6):650-4. [Crossref] [PubMed] [PMC]

34. Biradar A, Kori S, Patil N, Mudanur SR. Umbilical coiling index and its association with perinatal mortality and morbidity in a low resource tertiary care hospital of northern Karnataka-a prospective observational study. The New Indian Journal of OBGYN. 2020;7(1):105. [Crossref]

35. Raio L, Ghezzi F, Di Naro E, Franchi M, Maymon E, Mueller MD, et al. Prenatal diagnosis of a lean umbilical cord: a simple marker for the fetus at risk of being small for gestational age at birth. Ultrasound Obstet Gynecol. 1999;13(3):176-80. [Crossref] [PubMed]

36. Ugurlucan FG, Yuksel A. Is complete umbilical cord scanning possible at the secondtrimester ultrasound scan? J Clin Ultrasound. 2015;43(4):249-53. [Crossref] [PubMed]

37. Hussein MR, Mohammed RJ, Jameel AA. The umbilical coiling index in term of pregnancy as a marker of perinatal outcome. Ann Trop \& Public Health. 2020;23(7):816-23. [Crossref]

38. Predanic M, Perni SC, Chasen ST, Baergen RN, Chervenak FA. Ultrasound evaluation of abnormal umbilical cord coiling in second trimester of gestation in association with adverse pregnancy outcome. Am J Obstet Gynecol. 2005;193(2):387-94. [Crossref] [PubMed] 